ReviewArticle

\title{
Carbetocin versus Oxytocin for the Prevention of Postpartum Haemorrhage
}

\author{
P Begum $^{1}$, DR Saha ${ }^{2}$, Mahabuba $^{3}$, L Sanjowal ${ }^{4}$, MK Hasan ${ }^{5}$
}

\begin{abstract}
:
Postpartum haemorrhage is the leading cause of maternal mortality worldwide. Total $67-80 \%$ of cases are caused by uterine atony. Preventive measures include prophylactic drug use to aid uterine contraction after delivery, thus avoiding severe blood loss and reducing maternal morbidity and mortality. Carbetocin is a synthetic analogue of oxytocin with a long half-life which ensure more effective contraction and less adverse effects. It can be administered as a single dose injection either intravenously or intramuscularly rather than as an infusion over several hours as is the case with oxytocin. Carbetocin is currently indicated for prevention of uterine atony after delivery by caesarean section in spinal or epidural anaesthesia. A reduced need for additional uterotonics was observed with carbetocin vs. oxytocin in high-risk women and carbetocin was at least as effective as syntometrine in low-risk women. Carbetocin is effective treatment for the prevention of postpartum haemorrhage not only following caesarean delivery but also after vaginal delivery in high-risk women and those who suffer from hypertensive disorders in pregnancy. Further research is required to assess whether prophylactic carbetocin is superior to conventional uterotonic agents following vaginal delivery in low-risk women.
\end{abstract}

Key words: Carbetocin, Postpartum Haemorrhage.

\section{Introduction:}

The risk of postpartum haemorrhage is much higher for women undergoing caesarean section ${ }^{1,2}$. particularly in developing countries where the majority of operations are carried out as an emergency procedure ${ }^{3}$. Postpartum haemorrhage occurs in up to $15 \%$ of vaginal deliveries ${ }^{4}$ and represents the most important cause of maternal morbidity and mortality worldwide ${ }^{5,6}$. In most cases, uterine atony is responsible for the occurrence of excessive bleeding during or following childbirth ${ }^{7-9}$. Current strategies for preventing postpartum haemorrhage

1.Dr. Poly Begum, MBBS, FCPS (Obs \& Gynae), Assistant Professor, Department of Obstetrics \& Gynaecology, Diabetic Association Medical College, Faridpur.

2. Prof. Dr. Dipti Rani Shaha, MBBS, FCPS (Obs \& Gynae) Professor \& Head, Department of Obstetrics \& Gynaecology, Diabetic Association Medical College, Faridpur.

3. Dr. Mahbuba MBBS, FCPS (Obs \& Gynae), Associate Professor \& Head, Department of Obstetrics \& Gynaecology, Faridpur Medical College, Faridpur.

4. Dr. Lipika Sanjowal, MBBS, DA, MCPS (Anaesthesia), Associate Professor, Department of Anaesthesiology, Diabetic Association Medical College, Faridpur.

5. Dr. Md. Kamrul Hassan, MBBS, DCH (Pediatrics), Junior Consultant (Pediatrics), Charbhadrasan Upazila Health Complex, Faridpur.

Address of correspondence :

Dr. Poly Begum, MBBS, FCPS (Obs \& Gynae), Assistant

Professor, Department of Obstetrics \& Gynaecology, Diabetic Association Medical College, Faridpur. Cell: +88-01913-486864, E-mail: polyhassan008@gmail.com include the prophylactic use of uterotonic agents to enhance natural uterine contraction and retraction following caesarean section and in the third stage of labour for vaginal delivery ${ }^{9,10}$. Oxytocin is the most widely used uterotonic agent, but only has a half-life of 4-10 $\min ^{9-11}$. So must be administered as a continuous intravenous infusion to achieve sustained uterotonic activity. Another uterotonic drug frequently used in vaginal deliveries is syntometrine, which contains 5 $\mathrm{IU} / \mathrm{ml}$ oxytocin and $0.5 \mathrm{mg} / \mathrm{ml}$ ergometrine ${ }^{12,13}$. Syntometrine combines the rapid onset of action of oxytocin and the prolonged uterotonic effects of an ergot alkaloid. Intramuscular syntometrine use in active management of the third stage of labour is associated with a significant reduction in the risk of non-severe postpartum haemorrhage $(<1000 \mathrm{ml}$ of blood loss $)$ compared with intramuscular oxytocin ${ }^{12,13}$. Although intramuscular syntometrine is equally effective as intravenous oxytocin ${ }^{14}$, gastrointestinal and cardiovascular side effects such as maternal nausea, vomiting and raised blood pressure 12-14 are more frequent due to stimulation of smooth muscle contraction and vasoconstriction by ergometrine ${ }^{15,16}$. Oral and rectal administration of misoprostol, a synthetic analogue of prostaglandin E1, have demonstrated lower efficacy than injectable uterotonic agents in preventing excessive bleeding following vaginal delivery ${ }^{17,18}$ and are associated with a high incidence of shivering, fever and a possible risk of severe hyperthermia ${ }^{19,20}$. These factors deem misoprostol 
unsuitable for routine prevention of excessive postpartum bleeding in developed countries, despite low cost and ease of use $\mathrm{e}^{20,21}$. Although injectable prostaglandins such as prostaglandin 15-methyl F2 $\alpha$ or sulprostone can prevent excessive bleeding following vaginal delivery, safety concerns and cost limit their suitability for routine use in active management of the third stage of labour. However, they remain useful therapeutic options for postpartum haemorrhage treatment when other interventions prove ineffective ${ }^{21}$. Recent interest has focused on the prophylactic use of the oxytocin receptor agonist carbetocin ${ }^{22-29}$. Here we review the most recent clinical data regarding the efficacy of carbetocin in the prevention of postpartum haemorrhage following caesarean section and vaginal delivery, and provide an update on the safety and tolerability in comparison to conventional uterotonic agents.

\section{Pharmacology:}

Carbetocin is a long-acting synthetic analogue of oxytocin $^{30,31}$ that can be administered as a single-dose injection, either intravenously or intramuscularly ${ }^{32}$. Intravenously administered carbetocin has a half-life of approximately $40 \mathrm{~min}$, around 4-10 times longer than that reported for oxytocin. Following intramuscular injection, carbetocin reaches peak plasma concentrations in less than $30 \mathrm{~min}$ and has $80 \%$ bioavailability $^{32}$. The effect of various intravenous and intramuscular doses of carbetocin on the postpartum uterus has been evaluated by tocographic recordings of uterine contractions $24-48 \mathrm{~h}$ after vaginal delivery at term in 40 women $^{33}$. A single intravenous bolus of 8-30 $\mu \mathrm{g}$ carbetocin or a single intramuscular injection of 10 $70 \mu \mathrm{g}$ carbetocin produced a tetanic uterine contraction within 2 min of drug administration ${ }^{33}$. Uterine activity persisted for an average of $120 \mathrm{~min}$ following intramuscular injection and an average of $60 \mathrm{~min}$ following intravenous injection ${ }^{33}$. Thus, these data show that carbetocin onset of action is rapid irrespective of administration route, but duration of action is longer following intramuscular injection. The optimal carbetocin dose (intravenous or intramuscular) is $100 \mu \mathrm{g}^{34}$.

\section{Carbetocin at Caesarean Delivery:}

Carbetocin is currently approved in 23 countries for prevention of uterine atony and excessive bleeding following caesarean delivery in spinal or epidural anaesthesia. This therapeutic indication is supported by the results of two published controlled clinical trials ${ }^{35,36}$. The first study from Montreal (Canada) was a parallelgroup, randomised, double-blind, double-dummy trial, comparing uterotonic efficacy and safety of carbetocin and oxytocin in 57 women undergoing elective caesarean section $^{35}$. A single $100 \mu \mathrm{g}$ intravenous injection of carbetocin following placental delivery was at least as effective as a 16-h intravenous infusion of 32.5 IU oxytocin in controlling intraoperative blood loss. No significant differences in mean blood loss were observed between treatment groups (Table I). However, significantly fewer women in the carbetocin group $(53 \%)$ than in the oxytocin group $(79 \%)$ had blood loss of $\geq 200 \mathrm{ml}(\mathrm{p}=0.041)$ (Table I). The second study was a larger parallel-group, randomised, double-blind, double-dummy, Canadian multi-centre trial, comparing the efficacy and safety of carbetocin and oxytocin in 694 women undergoing elective caesarean section ${ }^{36}$. A single $100 \mu \mathrm{g}$ intravenous injection of carbetocin was more effective at preventing uterine atony than a $5 \mathrm{IU}$ intravenous bolus of oxytocin followed by intravenous infusion of $20 \mathrm{IU}$ over $8 \mathrm{~h}$; a significantly lower incidence of additional oxytocic interventions for treatment failure was observed in the carbetocin arm (Table I). Data from these two studies were pooled to determine overall treatment effect in a recent metaanalysis $^{29}$. The risk of postpartum haemorrhage, defined as a blood loss $\geq 500 \mathrm{ml}$, was not significantly decreased with carbetocin compared with oxytocin (relative risk $[\mathrm{RR}]=0.71$ and $95 \%$ confidence interval $[\mathrm{CI}]=0.14-3.53)$. However, carbetocin significantly reduced the need for subsequent interventions with uterotonic drugs $(\mathrm{RR}=0.44,95 \% \mathrm{CI}=0.25-0.78)$ or uterine massage $(\mathrm{RR}=0.38,95 \% \mathrm{CI}=0.18-0.80)$ compared with oxytocin. The authors ${ }^{29}$ also evaluated a randomised controlled trial published in abstract form ${ }^{37}$, comparing a single $100 \mu \mathrm{g}$ intravenous injection of carbetocin $(n=62)$ vs. placebo $(n=57)$ following elective caesarean section. Postpartum haemorrhage incidence was not reported as an outcome measure and could not be assessed, but the requirement for additional oxytocic therapy to prevent haemorrhage was significantly lower with carbetocin vs. placebo $(\mathrm{RR}=0.18,95 \% \mathrm{CI}=0.09-0.35)$. Moreover, women in the carbetocin group demonstrated a significant increase in uterine tone for $20 \mathrm{~min}$ following administration of study medication compared with placebo $(p<0.05)$. Another study, published in abstract form $^{36}$, investigated the efficacy of carbetocin vs. oxytocin for prevention of uterine atony in high-risk women undergoing delivery by caesarean section in Mexico (Table I). Risk factors included fetal macrosomia, polyhydramnios, low placental insertion, multiple gestation, prolonged labour, uterine myomas and chorioamnionitis. The main efficacy outcome measure was uterine atony incidence. A total of 77 women received carbetocin and 75 received oxytocin following caesarean delivery. Significantly fewer women experienced uterine atony after caesarean delivery with carbetocin (8\%) vs. oxytocin $(19 \%)$ (p < $0.0001)$. Blood loss $\geq 500 \mathrm{ml}$ was only observed in women who received oxytocin. 
Table-I : Prevention of postpartum haemorrhage: summary of carbetocin vs. oxytocin in caesarean delivery.

\begin{tabular}{|c|c|c|c|c|}
\hline Study & Population & Main Outcome & Carbetocin & Oxytocin \\
\hline RCT (29) & $\mathrm{n}=57$ elective & -Mean intraoperative & & \\
\hline delivery. & blood loss. & & $158 \mathrm{ml}$ & $188 \mathrm{ml}$ \\
\hline \multirow{4}{*}{ RCT (30) } & & -Blood loss $\geq 200 \mathrm{ml}$ & $53 \%$ & $79 \%$ \\
\hline & $\mathrm{n}=694$ elective & Additional oxytocic & & \\
\hline & delivery. & Intervention for & & \\
\hline & & uterine atony & $4.7 \%$ & $10.1 \%$ \\
\hline Randomised & $\mathrm{n}=152$ at high & -Uterine atony & $8 \%$ & $19 \%$ \\
\hline pragmatic & risk of $\mathrm{PPH}$ & -Intraoperative & & \\
\hline \multirow{2}{*}{\multicolumn{2}{|c|}{$\begin{array}{l}\text { clinical trial } \\
\text { (32) }\end{array}$}} & blood loss & -- & $500 \mathrm{ml}$ \\
\hline & & & & \\
\hline
\end{tabular}

RCT, Randomized Controlled Trial, PPH, Post Partum Haemorrhage

Table-II: Prevention of postpartum haemorrhage: summary of carbetocin vs. oxytocin in vaginal delivery.

\begin{tabular}{|c|c|c|c|c|}
\hline Study & Population & Main Outcome & Carbetocin & Oxytocin \\
\hline \multirow[t]{3}{*}{$\mathrm{RCT}(20)$} & \multirow{3}{*}{$\begin{array}{l}n=160 \text { at risk } \\
\text { of } P P H \text { required }\end{array}$} & -Uterine massage & $43.4 \%$ & $62.3 \%$ \\
\hline & & -Uterotonic intervention & & \\
\hline & & Clinically indicated & $44.6 \%$ & $63.6 \%$ \\
\hline \multirow[t]{4}{*}{ RCT (21) } & $\mathrm{n}=329$ & -Mean reduction in $\mathrm{Hb}$ & & \\
\hline & Singleton & concentration in $48 \mathrm{hrs}$ & $1.4 \mathrm{gm} / \mathrm{dl}$ & $1.5 \mathrm{gm} / \mathrm{dl}$ \\
\hline & Pregnancy & -Need for additional & & \\
\hline & \multicolumn{2}{|c|}{ Low PPH risk oxytocin injection } & $8.7 \%$ & $6.7 \%$ \\
\hline \multicolumn{2}{|c|}{ Retrospective $\mathrm{n}=118$ delivery } & -Mean blood loss & $388 \mathrm{ml}$ & $551 \mathrm{ml}$ \\
\hline \multirow[t]{2}{*}{ Study (22) } & at term in routine & -Blood loss $\geq 500 \mathrm{ml}$ & $21.4 \%$ & $43.5 \%$ \\
\hline & clinical setting & -Blood loss $\geq 1000 \mathrm{ml}$ & $1.8 \%$ & $14.5 \%$ \\
\hline
\end{tabular}

RCT, Randomized Controlled Trial, PPH, Post Partum Haemorrhage 


\section{Carbetocin in Vaginal Delivery:}

The efficacy of prophylactic carbetocin has also been investigated in prevention of postpartum haemorrhage following vaginal delivery. A randomised, doubleblind, placebo-controlled study has compared the efficacy of a single $100 \mu \mathrm{g}$ intramuscular dose of carbetocin with a 2-h intravenous infusion of $10 \mathrm{IU}$ oxytocin $^{26}$ (Table II). The study was conducted in two hospital centres in Canada and enrolled 160 women (83 in the carbetocin arm and 77 in the oxytocin arm) with $\geq 1$ known risk factor including: history of previous postpartum haemorrhage or retained placenta, grand multiparity, uterine overdistension related to multiple gestation, fetal macrosomia or polyhydramnios, chorioamnionitis, antepartum haemorrhage, induction or augmentation of labour with oxytocin for at least $4 \mathrm{~h}$, prolonged labour or rapid excessive labour. Treatment began immediately following placental delivery. The primary outcome measure was the need for additional uterotonic medications to prevent postpartum haemorrhage. Other efficacy variables included the need for uterine massage, change in haemoglobin and haematocrit over the initial $24 \mathrm{~h}$ postpartum, estimated blood loss following study drug administration to the end of delivery, uterine tone and amount/type of lochia. The number of women requiring additional uterotonic medication was comparable between treatment groups but significantly fewer women required at least one uterine massage following treatment with carbetocin $(43.4 \%)$ vs. oxytocin $(62.3 \%) \quad(p<0.025)$. Overall, uterotonic intervention (either additional uterotonic agents or uterine massage) was required in $44.6 \%$ of women who received carbetocin and in $63.6 \%$ of women who received oxytocin, a statistically significant difference $(\mathrm{p}<0.025)$.

No significant differences were observed between treatment groups for other efficacy variables. The investigators concluded that a single intramuscular injection of carbetocin is more likely to prevent postpartum haemorrhage in high-risk women than a continuous intravenous infusion of oxytocin. Another randomised, double-blind, controlled trial has compared efficacy and safety of intramuscular carbetocin with intramuscular syntometrine in preventing primary postpartum haemorrhage in lowrisk women with singleton pregnancy achieving vaginal delivery from 34 weeks ${ }^{27}$ (Table II). The setting was the delivery suite of a university-based obstetric unit in Hong Kong. A total of 329 women were randomised to receive either a single intramuscular injection of 100 $\mu \mathrm{g}$ carbetocin $(\mathrm{n}=165)$ or a single intramuscular injection of $1 \mathrm{ml}$ syntometrine (5 IU oxytocin and 0.5 $\mathrm{mg}$ ergometrine) $(\mathrm{n}=164)$ after the second stage of labour (following anterior shoulder delivery). The primary efficacy outcome was reduction in haemoglobin levels from admission to the labour ward until $48 \mathrm{~h}$ after delivery. Secondary efficacy outcomes included the need for additional oxytocin injections, the incidence of $\geq 500 \mathrm{ml}$ blood loss and the incidence of retained placenta. The study did not demonstrate significant differences between treatment arms for any of the efficacy outcomes. Thus, intramuscular carbetocin was considered as effective as intramuscular syntometrine in preventing primary postpartum haemorrhage following vaginal delivery in low-risk women. A recent retrospective study has also compared carbetocin efficacy with combined use of oxytocin and ergometrine following routine vaginal delivery in Macau, China ${ }^{28}$ (Table II). Women $(\mathrm{n}=118)$ received either a single intramuscular injection of $100 \mu \mathrm{g}$ carbetocin or a single intramuscular injection of 5 IU oxytocin and $0.2 \mathrm{mg}$ ergometrine immediately following delivery. Significantly less blood loss was observed with carbetocin compared with oxytocin and ergometrine $(p=0.01)$, with a mean difference between treatment groups of $163 \mathrm{ml}$. Postpartum haemorrhage incidence, defined as blood loss $\geq 500 \mathrm{ml}$, was significantly lower in the carbetocin group $(21.4 \%)$ than in the combination group $(43.5 \%)(\mathrm{p}=0.01)$. Notably, nine patients $(14.5 \%)$ in the combination group experienced $\geq 1000 \mathrm{ml}$ blood loss compared with one patient $(1.8 \%)$ in the carbetocin group $(\mathrm{p}=0.02)$, and a significantly greater reduction in haematocrit was observed with oxytocin and ergometrine compared with carbetocin. The authors concluded that carbetocin should be considered a good alternative to conventional uterotonics in preventing postpartum haemorrhage after vaginal delivery. In this retrospective study, carbetocin displayed significantly better uterotonic activity than an oxytocin/ ergometrine combination containing less than half the ergometrine dose contained in syntometrine ${ }^{27}$. However, these findings are still of interest as these retrospective data more closely reflect everyday clinical practice.

\section{Pharmacological Studies in Volunteers:}

In pharmacokinetic and dose-tolerance studies, up to $400 \mu \mathrm{g}$ of intravenous or intramuscular carbetocin was associated with the occurrence of minimal adverse effects (mainly facial flushing and feeling of warmth) in non-pregnant women ${ }^{32}$. After intramuscular administration of 400 and $800 \mu \mathrm{g}$, a significant increase in pulse rate was observed ${ }^{32}$. A study assessing uterotonic effects of various doses of intramuscular or intravenous carbetocin on the postpartum uterus 24-48 $\mathrm{h}$ following vaginal delivery at term ${ }^{33}$ revealed that carbetocin produced mild abdominal cramping in most women. Severe abdominal pain was reported by three women who received doses of 50 or $100 \mu \mathrm{g}$ intravenously or $70 \mu \mathrm{g}$ intramuscularly. Less frequently reported adverse events were back pain, facial flushing and feeling of warmth. Similar to the study previously mentioned $^{32}$ a transient increase in pulse rate occurred 
5 min after intramuscular administration of $\geq 70 \mu \mathrm{g}$ carbetocin $(78.5 \pm 0.7$ to $81.7 \pm 0.07$ beats $/ \mathrm{min})$, not reaching the level of tachycardia. A significant decrease in blood pressure was not observed. A mild increase in blood pressure (max. 140/80 $\mathrm{mmHg}$ ) that produced distressing abdominal pain was found in only two patients following intravenous injection doses (50 and $100 \mu \mathrm{g})$. In an ascending dose-tolerance study with intramuscular carbetocin ${ }^{36}$, a single injection of carbetocin (range 15-200 $\mu \mathrm{g}$ ) was administered immediately after birth to healthy women who delivered vaginally at term. There was no dose dependent effect on blood pressure, heart rate and respiratory rate and no cases of nausea, vomiting or pruritus were reported. Incidence of abdominal pain and tremor were $27 \%$ and $40 \%$, respectively. Abdominal pain was only severe enough to suggest a possible link with carbetocin in one case $(2 \%)^{34}$. There were six cases of $\geq 1000 \mathrm{ml}$ blood loss and four cases of retained placenta ${ }^{34}$. Most of these serious adverse events occurred in women who had received the highest dose of intramuscular carbetocin $(200 \mu \mathrm{g})$ and only the retained placenta cases were considered to be possibly linked to carbetocin use by the investigators ${ }^{34,36}$. Lowest blood loss was recorded with 75-125 $\mu \mathrm{g}$ carbetocin and drug-related serious adverse events were not evident until at least $125 \mu \mathrm{g}$ was administered. These findings confirm that the intramuscular dose of $100 \mu \mathrm{g}$ carbetocin, effectively used for prevention of uterine atony following vaginal delivery in all recently published studies ${ }^{26-28}$, is the optimal dose with respect to safety and tolerability. Another study evaluated drug transfer to breast milk following intramuscular injection of $70 \mu \mathrm{g}$ carbetocin in five healthy women (7-14 weeks postpartum $)^{40}$. The mean AUC of carbetocin concentration in breast milk over 240 min following drug administration was 50 times lower than plasma concentration (18.6 and 29.0 $\mathrm{pg} / \mathrm{ml}$ for the right and left breast, respectively, compared with $1119.3 \mathrm{pg} / \mathrm{ml}$ in plasma). The small amounts transferred from plasma into colostrum or breast milk following a single injection of carbetocin presents little risk to breast-fed infants ${ }^{40}$. Since carbetocin is a peptide, a small amount of drug ingested by an infant is assumed to be rapidly degraded by gut enzymes $^{39,40}$.

\section{Effectiveness in Caesarean Delivery:}

Adverse events reported by $\geq 10 \%$ of women who received prophylactic intravenous carbetocin following caesarean delivery were headache, tremor, hypotension, flushing, nausea, abdominal pain, pruritus and feeling of warmth (Table III) ${ }^{39}$. In the trial comparing carbetocin with placebo, flushing, abdominal pain and pruritus were more frequently observed with carbetocin and the drug was associated with decreased blood pressure and transient tachycardia ${ }^{31,37}$. Adverse events observed in the carbetocin vs. oxytocin trials were similar in type and frequency between treatment $\mathrm{arms}^{35-}$ ${ }^{36,39}$ and the meta-analysis from these trials confirmed that the risk of experiencing headache, tremor, dizziness, flushing, shortness of breath, premature ventricular contractions/tachycardia, abdominal pain, nausea, vomiting, metallic taste, pruritus, back pain, feeling of warmth, chills or sweating was similar with carbetocin or oxytocin ${ }^{29}$.

Table-III: Adverse effects observed in clinical trials with carbetocin following caesarean section after administration under spinal or epidural anaesthesia ${ }^{39}$.

\begin{tabular}{lll}
\hline System & $\begin{array}{l}\text { Very } \\
\text { Common }\end{array}$ & $\begin{array}{l}\text { Common } \\
\text { Sporadic } \\
\text { or }\end{array}$ \\
\hline $\begin{array}{l}\text { Blood and } \\
\text { lymphatic } \\
\text { system }\end{array}$ & Anaemia \\
\hline
\end{tabular}

$\begin{array}{ll}\text { Nervous } & \begin{array}{l}\text { Headache, } \\ \text { system }\end{array} \\ \text { tremor }\end{array}$

Vascular Hypotension, Dizziness flushing

Respiratory, Chest pain, Tachycardia thoracic dyspnoea

and

mediastinal

Gastroin- Abdominal Metallic taste, testinal pain, Nausea vomiting

Skin and

subcuta-

neous tissue

General and Feeling of warmth

administration Chills, Sweating site conditions pain 


\section{Effectiveness in Vaginal Delivery:}

Use of carbetocin in vaginal delivery also revealed a similar safety profile to oxytocin ${ }^{26}$. The incidence of dizziness, tremor and vasodilation were comparable between treatment arms. However, the incidence of headache was 2 -fold lower with carbetocin $(7.2 \%)$ vs. oxytocin $(14.3 \%)$, and vomiting $(7.8 \%)$ and pruritus $(5.2 \%)$ were only reported in the oxytocin arm. Conversely, abdominal pain was only reported in women who received carbetocin $(6 \%)$. Other adverse events previously reported (e.g. increased pulse, decreased diastolic blood pressure and feeling of warmth) were not observed in this trial ${ }^{26}$. Comparison of adverse events with carbetocin and syntometrine revealed that nausea and vomiting were significantly reduced with carbetocin ${ }^{27}$. Facial flushing and pain at the injection site were only reported in the syntometrine arm $(2 \%$ and $0.7 \%$, respectively). Hypertension (defined as blood pressure $\geq 140 / 90 \mathrm{mmHg}$ ) at 30 and 60 min following delivery was $5.3 \%$ and $4 \%$ in the syntometrine group, respectively, whereas hypertension was not observed in the carbetocin group at either time point. However, $21.3 \%$ experienced tachycardia (defined as maternal pulse $\geq 100$ beats $/ \mathrm{min}$ ) within 60 min of delivery with carbetocin, compared with $12.7 \%$ in the syntometrine group. The duration of tachycardia was not reported in this study. Only one out of 150 women $(0.7 \%)$ in the carbetocin group required manual removal of retained placenta compared with three out of 150 women $(2 \%)$ in the syntometrine group. The retrospective study comparing carbetocin with the combination of oxytocin and ergometrine did not report any safety and tolerability data ${ }^{26}$.

\section{Cost- Effectiveness of Carbetocin Vs Oxytocin:}

One study from Mexico has compared costeffectiveness of prophylactic carbetocin and oxytocin following caesarean section ${ }^{36}$. Cost-effectiveness was modeled from the perspective of the third party payer (Mexican Institute of Social Security) and resource use was obtained from the clinical trial data (Table I). Costs were estimated using the financial information provided by the Mexican Institute of Social Security and were reported in USD. Univariate and probabilistic sensitivity analyses were performed using probability distribution data from the clinical trial and the Monte Carlo Simulation technique ${ }^{41}$. The mean cost per woman was significantly lower following carbetocin treatment (3525 USD) compared with oxytocin treatment (4054 USD) $(\mathrm{p}<0.0001)$. The mean costeffectiveness ratio was 3874 USD for carbetocin and 4944 USD for oxytocin. The incremental costeffectiveness ratio revealed that carbetocin was dominant and the cost-effectiveness acceptability curve and net health benefits demonstrated that carbetocin was superior to oxytocin independently of the willingness- to-pay threshold.

\section{Conclusion:}

Carbetocin is a long-acting synthetic analogue of oxytocin that combines the safety and tolerability profile of oxytocin with the sustained uterotonic activity of ergometrine and is currently indicated for the prevention of uterine atony following caesarean delivery. Evidence from three randomized controlled trials indicates that a single intravenous injection of 100 $\mu \mathrm{g}$ carbetocin significantly reduces the need for additional uterotonic interventions to maintain adequate uterine tone and prevent/treat excessive bleeding following caesarean delivery vs. placebo or intravenous oxytocin. Furthermore, the administration of a single injection of carbetocin is more convenient than an oxytocin infusion, which requires an intravenous line and is time consuming. In high-risk women, carbetocin is superior to oxytocin in preventing $\geq 500 \mathrm{ml}$ of blood loss following caesarean section and may represent the most cost-effective uterotonic drug in developing countries with low resources, as suggested by the results of the clinical trial conducted in Mexico. Two recent randomized controlled clinical trials and one retrospective study have indicated that carbetocin may also represent a good alternative to conventional uterotonic agents for prevention of postpartum haemorrhage after vaginal delivery. When administered as a single $100 \mu \mathrm{g}$ dose, carbetocin has demonstrated longer duration of action compared with intravenous oxytocin, as indicated by the reduced need for additional uterotonic interventions in high-risk women with carbetocin. Carbetocin is also at least as effective as syntometrine for management of the third stage of labour in low-risk women. Carbetocin has been associated with a low incidence of adverse effects, with a similar tolerability profile to intravenous oxytocin. It has also been associated with a lower incidence of gastrointestinal side effects compared with the combination of oxytocin and ergometrine. A higher rate of tachycardia has been reported with carbetocin vs. syntometrine. Tachycardia duration was not reported, but based on available data from other trial, a transitory and slight increase of no clinical relevance would be expected. In this context it must be taken into account that the definition of physiological tachycardia in pregnancy ranges from 100 to 120 beats $/ \mathrm{min}$. Carbetocin appears to have a better cardiovascular sideeffect profile than oxytocin or syntometrine. However, data from the hitherto published literature are limited. The effect of carbetocin on blood pressure needs further investigation, and preeclampsia remains a contraindication to the use of carbetocin. Available data are encouraging to suggest carbetocin could become useful for prevention of postpartum haemorrhage even in preeclamptic pregnant women. Nevertheless, the careful assessment of the patient's history and close blood pressure monitoring are mandatory in each patient treated with carbetocin, in particular in those with suspected preexisting cardiovascular disease. The 
promising findings from these studies suggest that carbetocin may become the drug of choice for prevention of postpartum haemorrhage after vaginal delivery in high-risk women. More trials in low-risk women who undergo vaginal delivery are needed to assess whether carbetocin is superior to conventional uterotonic drugs for the majority of pregnant women. Also, further studies could be conducted to determine if single intramuscular administration of carbetocin is advantageous in settings where prophylactic use of intravenous uterotonics is unsafe or impracticable, like in domiciliary practice or in third stage of labour management in developing countries.

\section{References :}

1. Leduc D, Senikas V, Lalonde A. Active management of the third stage of labour: prevention and treatment of postpartum hemorrhage. J Obstet Gynaecol Can 2009; 31:980-93.

2. World Health Organization. Recommendations for the Prevention of Postpartum Haemorrhage. WHO/MPS/07.06. Geneva: WHO, 2007.

3. Peters NCJ, Duvekot JJ. Carbetocin for the prevention of postpartum hemorrhage: a systematic review. Obstet Gynecol Surv $2009 ; 64: 129-35$.

4. Vercauteren M, Palit S, Soetens F, Jacquemyn Y, Alahuhta S. Anaesthesiological considerations on tocolytic and uterotonic therapy in obstetrics. Acta Anaesthesiol Scand 2009; 53:701-09.

5. Prendiville W, Elbourne D, Chalmers I. The effects of routine oxytocic administration in the management of the third stage of labor: an overview of the evidence from controlled clinical trials. Br J Obstet Gynecol 1988; 95:3-16.

6. Rochat RW, Koonin LM, Atrash HK, Jewett JF. The Maternal Mortality Collaborative. Maternal mortality in the United States: report from the Maternal Mortality Collaborative. Obstet Gynecol 1988; 72:91-7.

7. Li XF, Fortney JA, Kotelchuck M, Glover LH. The postpartum period: the key to maternal mortality. Int $\mathrm{J}$ Gynecol Obstet 1996; 54:1-10.

8. World Health Organization. Global estimates of maternal mortality for 1995: results of an in-depth review analysis and estimation strategy (statement). Geneva: World Health Organization; 2001.

9. Bouwmeester FW, Boltc AC, van Geijn HP. Pharmacological and surgical therapy for primary postpartum haemorrhage. Curr Pharm Des 2005; 11:759-73.

10. Chong Y-S, Su L-L, Arulkumaran S. Current strategies for the prevention of postpartum haemorrhage in the third stage of labour. Curr Opin Obstet Gynecol 2004; 16:143-50.

11. Wedisinghe L, Macleod M, Murphy DJ. Use of oxytocin to prevent haemorrhage at caesarean section-a survey of practice in the United Kingdom. Eur J Obstet Gynecol Reprod Biol $2008 ; 137: 27-30$.

12. Ozumba BC, Ezegwui HU. Blood transfusion and caesarean section in a developing country. J Obstet Gynecol 2006; 26:746-48.
13. Ryden G, Sjoholm J. Half-life of oxytocin in blood of pregnant and nonpregnant women. Acta Endocrinol (Copenh) 1969; 61:425-31.

14. Fabian M, Forsling M, Jones J. The clearance and antidiuretic potency of neurohypophysal hormones in man, and their plasma binding and stability. J Physiol 1969; 204:653-58.

15. Chard T, Boyd N, Forsling M. The development of a radioimmunoassay for oxytocin: the extraction of oxytocin from plasma, and its measurement during parturition in human and goat blood. J Endocrinol 1970; 48:223-34.

16. McDonald S, Abbott JM, Higgins SP. Prophylactic ergometrineoxytocin versus oxytocin for the third stage of labour. Cochrane Database Syst Rev; 2004

17. Ferring Inc. Product monograph: Duratocin (Carbetocin Injection). 2006.

18. Dyer RA, Dyk D van, Dresner A. The use of uterotonic drugs during caesarean section. Int J Obstet Anesth 2010; 19:313-19.

19. Liabsuetrakul T, Choobun T, Peeyanajarassri K, Islam QM. Prophylactic use of ergot alkaloids in the third stage of labour Cochrane Database Syst Rev; 2007.

20. Choy CM, Lau WC, Tam WH, Yuen PM. A randomized controlled trial of intramuscular syntometrine and intravenous oxytocin in the management of the third stage of labour. BJOG 2002; 109:173-77.

21. Dumoulin JG. A reappraisal of the use of ergometrine. J Obstet Gynecol 1981; 1:178-81.

22. Carey M. Adverse cardiovascular sequelae of ergometrine. Br J Obstet Gynecol 1993; 100:865.

23. Gu" Imezoglu AM, Forna F, Villar J, Hofmeyr GJ. Prostaglandins for prevention of Postpartum haemorrhage. Cochrane Database Syst Rev; 2004

24. Villar J, Gu“ lmezoglu AM, Hofmeyr GJ, Forna F. Systematic review of randomized controlled trials of misoprostol to prevent postpartum haemorrhage. Obstet Gynecol 2002; 100:1301-12.

25. Chong YS, Chua S, Arulkumaran S. Severe hyperthermia following oral misoprostol in the immediate postpartum period. Obstet Gynecol 1997; 90:703-04.

26. Boucher M, Nimrod CA, Tawagi GF, Meeker TA, Rennicks White RE, Vann J. Comparison of carbetocin and oxytocin for the prevention of postpartum haemorrhage following vaginal delivery: a double-blind randomized trial. J Obstet Gynecol Can 2004; $26: 481-88$

27. Leung SW, Ng PS, Wong WY, Cheung TH. A randomized trial of carbetocin versus syntometrine in the management of the third stage of labour. BJOG 2006; 113:1459-64.

28. Ngan L, KeongW, Martins R. Carbetocin versus a combination of oxytocin and ergometrine in control of postpartum blood loss. Int J Gynecol Obstet 2007; 97:152-53.

29. Su LL, Chong YS, Samuel M. Oxytocin agonists for preventing postpartum haemorrhage. Cochrane Database Syst Rev; 2007.

30. Atke A, Vilhardt H. Uterotonic activity and myometrial receptor affinity of Ideamino- I-carba-2-tyrosine (O-methyl) oxytocin. Acta Endocrinol (Copenh) 1987; 19:971-76. 
31. Sweeney G, Holbrook AM, Levine M. Pharmacokinetics of carbetocin, a long-acting oxytocin analogue, in nonpregnant women. Curr Ther Res 1990; 47:520-40.

32. Hunter DJ, Schulz P, Wassenaar W. Effect of carbetocin, a longacting oxytocin analogue in the postpartum uterus. Clin Pharmacol Ther 1992; 52:60-67.

33. Van Dongen PW, Verbruggen MM, de Groot ANJA, van Roosmalen J, SporkenJMJ, Schulz M. Ascending dose tolerance study of intramuscular carbetocin administered after normal vaginal birth. Eur J Obstet Gynecol Reprod Biol 1998; 77:181-87.

34. Boucher M, Horbay GLA, Griffin P, Deschamps Y, Desjardins C, Schulz M, et al. Double-blind, randomized comparison of the effect of carbetocin and oxytocin on intraoperative blood loss and uterine tone of patients undergoing cesarean section. J Perinatol 1998; 18:202-07.

35. Dansereau J, Joshi AK, Helewa ME. Double-blind comparison of carbetocin versus oxytocin in prevention of uterine atony after cesarean section. Am J Obstet Gynecol 1999; 180:670-76.

36. Barton SR, Jackson A. The safety and efficiency of carbetocin to control uterine bleeding following caesarean section. Prenat Neonatal Med 1996; 1:185.

37. Del Angel-Garcia G, Garcia-Contreras F, Constantino-Casas P. Economic evaluation of carbetocine for the prevention of uterine atony in patients with risk factors in Mexico. Value Health 2006; 9(6):A254.

38. Ferring Pharmaceuticals: Global Pharmacovigilance. Periodic safety update report for carbetocin. 17 July 2006. On file at Ferring Pharmaceutical A/S, Copenhagen. Denmark.

39. Silcox J, Schulz P, Horbay GLA, Wassenaar W. Transfer of carbetocin into human breast milk. Obstet Gynecol 1993; 82:456-59.

40. Doubilet P, Begg CB, Weinstein MC, Braun P, McNeil BJ. Probabilistic sensitivity analysis using Monte Carlo Simulation. A practical approach. Med Decis Making 1985; 5:157-77.

41. Ngan L, Keong W, Martins R. Carbetocin versus a combination of oxytocin and ergometrine in control of postpartum blood loss. Int J Gynaecol Obstet 2007; 97:152-53.

42. Su LL, Rauff M, Chan YH. Carbetocin versus syntometrine for the third stage of labour following vaginal delivery-a double-blind randomised controlled trial. BJOG 2009; 116:1461-66.

43. Thomas JS, Koh SH, Cooper GM. Haemodynamic effects of oxytocin given as i.v. bolus or infusion on women undergoing Caesarean section. Br J Anaesth 2007; 98:116-19.

44. Tsen LC, Balki M. Oxytocin protocols during cesarean delivery: time to acknowledge the risk/benefit ratio? Int J Obstet Anesth 2010; 19:243-45. 